\title{
Extended Endoscopic Endonasal Approach for Cerebral Aneurysm: What we Know Today
}

\author{
Anil Kumar* \\ Department of Neurosurgery, All India Institute of Medical Sciences, Raipur, India \\ *Corresponding Author: Anil Kumar, Department of Neurosurgery, All India In- \\ stitute of Medical Sciences, Raipur, India.
}

Received: December 31, 2019

Published: January 07, 2020

(C) All rights are reserved by Anil Kumar.
The management of cerebral aneurysms continues to evolve as a result of the on going search for safer and more effective treatment options. The significant advancement in the endoscopic endonasal techniques has encouraged neurosurgeons to utilize the extended endoscopic endonasal approach (EEA) for cerebral aneurysm clipping [1,2]. Initially, the endoscope was used primarily as an adjunct to the microscope to clip cerebral aneurysm via craniotomy and it has been found as a safe and effective tool for better visualization of cerebrovascular branch points and for better exposure around the aneurysm [3]. EEA to the skull base is a growing technique with promising results in the treatment of many skull base pathologies. It has been showed that extended endoscopic endonasal approaches offer the likelihood of exposing the entire midline skull base from below to reach the brain with its surrounding neu $\neg$ rovascular structures [4]. When applied to vascular surgery, the EEA offers some benefits due to the properties of the endoscope itself and minimal invasiveness of technique like lack of brain retraction, direct access to the aneurysm, minimal manipulation of the complex neurovascular structures, better exposure "around the aneurysm", a close and detailed visualization of the neurovascular structures and to be sure of full exclusion of the aneurysm from the main cerebral circulation, avoidance of skin incisions and a more comfortable postoperative recovery [2,5]. For well-selected cases, this minimally invasive approach may provide a better visualization of the operative field, an equivalent vascular control and direct access to the aneurysm and parent artery, easy access to proximal internal carotid artery control without another incision, no brain parenchyma or any other neurovascular structures between the surgeon and the aneurysm leading to direct surgical corridor compared to transcranial approaches [2,5].

The endoscopic endonasal approach when applied to cerebral aneurysm has several limitations that should be taken into consi- deration such as narrow surgical corridor, requirement of lower profile aneurysm clips and appliers, and challenges with handling potential intraoperative rupture which may cloud the endoscope and hamper visualization,, the inability to perform cerebral revascularization or anastomosis, and steep learning curve $[1,2,5]$. It is important to note that in the setting of subarachnoid hemorrhage and potential communicating hydrocephalus or elevated intracranial pressure, meticulous attention towards robust Dural reconstruction is obligatory. However, the choice of the EEA must be weighed not only against the traditional transcranial approaches for cerebral aneurysm, but also against endovascular approaches. The extended endonasal approach has gained lot of attention since Kassam., et al. published the first case of an EEA for vertebral artery aneurysm clipping in 2006 [6].

The purely endoscopic approach has the potential to emerge as a safe, effective, and advantageous alternative to transcranial and endovascular options for selected group of patients and further improvements in operative technology, including advances in endoscopic visualization, may further alter the landscape of treatment involving this complex pathology.

\section{Bibliography}

1. Xiao LM., et al. "The Endoscopic endonasal clipping of anterior circulation aneurysm: surgical techniques and results". World Neurosurgery (2018).

2. Kumar A., et al. "The Endoscopic endonasal clipping of cerebral aneurysms: started from the bottom, now we here". Journal of Neurosurgical Sciences (2018).

3. Peris-Celda M., et al. "The Surgical anatomy of endoscope-assisted approaches to common aneurysm sites". Neurosurgery 10.1 (2014): 121-144. 
4. Cavallo LM., et al. "The Endoscopic endonasal surgery of the midline skull base: anatomical study and clinical considerations". Neurosurgical Focus 19.1 (2005): E2.

5. Di Somma A., et al. "The Extended endoscopic endonasal approaches for cerebral aneurysms: anatomical, virtual reality and morphometric study". Biomed Research International (2014): 703-792.

6. Kassam AB., et al. "The expanded endonasal approach for an endoscopic transnasal clipping and aneurysmorrhaphy of a large vertebral artery aneurysm: technical case report". Neurosurgery 59.1-1 (2006).

\section{Assets from publication with us}

- Prompt Acknowledgement after receiving the article

- Thorough Double blinded peer review

- Rapid Publication

- Issue of Publication Certificate

- High visibility of your Published work

Website: https://www.actascientific.com/

Submit Article: https://www.actascientific.com/submission.php

Email us: editor@actascientific.com

Contact us: +919182824667 